\title{
Foam pads properties and their effects on posturography in participants of different weight
}

\author{
Guy Gosselin* and Michael Fagan
}

\begin{abstract}
Background: Foam pads are increasingly used on force platforms during balance assessments in order to produce increased instability thereby permitting the measurement of enhanced posturographic parameters. A variety of foam pads providing different material properties have thus been used, although it is still unclear which characteristics produce the most effective and reliable tests. Furthermore, the effects of participant bodyweight on the performance of the foam pads and outcome of the test are unknown. This project investigated how different foam samples affected postural sway velocity in participants of different weights.

Method: Four foam types were tested according to a modified American Society for Testing and Materials standard method for testing flexible cellular materials. Thirty-six healthy male factory workers divided into three groups according to body mass were tested three times for each of the 13 randomly-selected experimental situations for changes in postural sway velocity in this cross-over study. Descriptive and inferential statistics were used to compare the results and evaluate the difference in sway velocity between mass groups.

Results: For the materials considered here, the modulus of elasticity of the foam pads when compressed by $25 \%$ of their original heights was inversely proportional to their density. The largest changes in postural sway velocity were measured when the pads of highest stiffness were used, with memory foam pads being the least likely to produce significant changes.

Conclusions: The type of foam pads used in posturography is indeed important. Our study shows that the samples with a higher modulus of elasticity produced the largest change in postural sway velocity during quiet stance. The results suggest that foam pads used for static computerised posturography should 1) possess a higher modulus of elasticity and 2) show linear deformation properties matched to the participants' weight.
\end{abstract}

Keywords: Balance, Foam pads, Posturography, Modulus of elasticity, Biomechanics

\section{Background}

Posturography has been shown to be useful in the workplace, for example to assess different-aged workers in physically demanding jobs [1], determine the effects of obesity on balance [2], to measure sleepiness and fatigue [3], and even to observe the effects of neurotoxicity due to workers exposure to organic solvent mixtures [4]. Furthermore, there is now a trend in western countries to increase the age of retirement [5]. This aging workforce may in some instances be placed at risk should their functional capacities such as balance become altered. Approximately one person in three over

\footnotetext{
* Correspondence: g.gosselin@2010.hull.ac.uk

School of Engineering, University of Hull, Cottingham Road, Kingston-upon-Hull HU6 7RX, UK
}

C Biomed Central

(c) 2015 Gosselin and Fagan; licensee BioMed Central. This is an Open Access article distributed under the terms of the Creative Commons Attribution License (http://creativecommons.org/licenses/by/4.0), which permits unrestricted use, distribution, and reproduction in any medium, provided the original work is properly credited. The Creative Commons Public Domain Dedication waiver (http://creativecommons.org/publicdomain/zero/1.0/) applies to the data made available in this article, unless otherwise stated. the age of 65 has at least one fall a year and one person in five who falls after the age of 65 for reasons connected with balance dies in the year following the fall [6]. In addition obese adults fall nearly twice as often as their non-obese counterparts [7]. All this motivates researchers and clinicians to develop new ways to understand and quantify postural stability.

Postural stability is often assessed by measuring the centre of pressure (COP) which is a point where the vertical reaction forces of the ground act. It represents the weighted average of all pressures over the body in contact with the ground. As such, there are numerous COP measures such as average velocity of COP, COP excursion, average radial displacement of the COP, to name a few; however until recently it was not evident which measure 
is optimal [8]. Mahdavi-Amiri et al. have shown that during static posturography the average velocity for a given stability condition, is more repeatable (less variable) between trials from a data collection session, and more discernible between the different stability conditions [9].

Many of the modern assessments systems use dynamic posturographic devices, which are sophisticated apparatus that introduce instability along with altered visual cues [10]. Unfortunately the high costs of such systems together with their large size prevent their general use in industry. Static computerised posturography represents a low-cost alternative, although the current high variability of results limits the accuracy of the conclusions that can be drawn from such assessments [11].

Recently, foam pads have been used on force platforms in order to induce increased instability thereby decreasing the coefficient of variation $(\mathrm{CV})$ to a more acceptable level [12]. The use of foam pads in posturography is thought to exagerate balance deficits by altering the reliability of somatosensory input from cutaneous mechanoreceptors on the plantar soles. Previous research looking at the effect of the surface on which posturography is performed has shown that the type of foam has different effects on balance [11,13]. Although it is still unclear which characteristics produce the optimal performance, De Berardino and colleagues suggested that using foam pads of higher stiffness was best for clinical use [11]. More specific information is therefore essential before a standardised protocol can be proposed. Foam pads used in posturography will behave as any other material when placed under load, i.e. the deflection will be proportional to both the force, by a property known as the stiffness of the structure, and proportional to the property of the material itself called the modulus of elasticity [14].

Few papers have reported the material characteristics of foam pads used in posturography. Blackburn (2003) [15] investigated the kinematic analysis of the hip and trunk during bilateral stance on firm foam and multiaxial support surfaces. In this instance the height of the foam blocks was not mentioned but the density was reported as $54.53 \mathrm{~kg} / \mathrm{m}^{3}$ [15]. Another study that looked into trunk sway measurements during stance and gait tasks in Parkinson's disease [16], used foam pads with a height of $10 \mathrm{~cm}$ and a density of $25 \mathrm{~kg} / \mathrm{m}^{3}$. Finally, Di Bernardino et al. [11] evaluated the postural effects of standing on two different types of rubber foam pads: a "monolayer" with a thickness of $10 \mathrm{~cm}$ and a density of $25 \mathrm{~kg} / \mathrm{m}^{3}$, and a "bilayer" pad with a thickness of $8 \mathrm{~cm}$ and a density of $100 \mathrm{~kg} / \mathrm{m}^{3}$. Their results show that the variability of static posturography parameters was significantly reduced by the use of both foam pads. However, the comparison of the two types was also statistically significant, with the bilayer type presenting the lowest $\mathrm{CV}$ in the results of $10 \%$, compared with $14.4 \%$ for the monolayer.
Unfortunately, the bi-layer foam pad described by $\mathrm{Di}$ Berardino is a specialist product that it is not readily available outside of Italy.

To the best of our knowledge no one has investigated the postural effects of participants of different mass and the effects of plantar surface area on different types of foam. One would assume that the postural effects of standing on a specific foam pad sample would be different for lighter and heavier participants. Thus, this study's main purpose was to determine how a range of foam pads (including bilayer foam pad combinations) influenced postural sway velocity during quiet stance for subjects of different body mass. The null hypothesis tested was: there is no difference in sway velocity when any of the foam pads are used.

\section{Method}

\section{Foam pads material properties}

The properties of the pads were measured using three tests based on ASTM test D-3574-11 [17]. Uniaxial compression was achieved using a screw driven test machine (LR $100 \mathrm{~K}$, Lloyds Instrument, Bognor Regis, UK) with a $100 \mathrm{kN}$ load cell (Figure 1). The press was remotely controlled via a desktop computer running Nexygen software (Lloyds Instrument, Bognor Regis, UK). Four foam pads were obtained from three sources: 1) rehabilitation material supplier, 2) online foam shop and 3) upholstery high street shop (Table 1). The pads had a size of $480 \times 480 \mathrm{~mm}$, with the exception of the rehabilitation balance pad which had a smaller size of $440 \times 400 \mathrm{~mm}$. The atmospheric pressure in the laboratory was $1015 \mathrm{hPa}$ and the temperature was $22^{\circ} \mathrm{C}$.

\section{Test A: density test}

The density of the uncored foam was calculated from the mass and volume of each specimen. The pad's dimensions

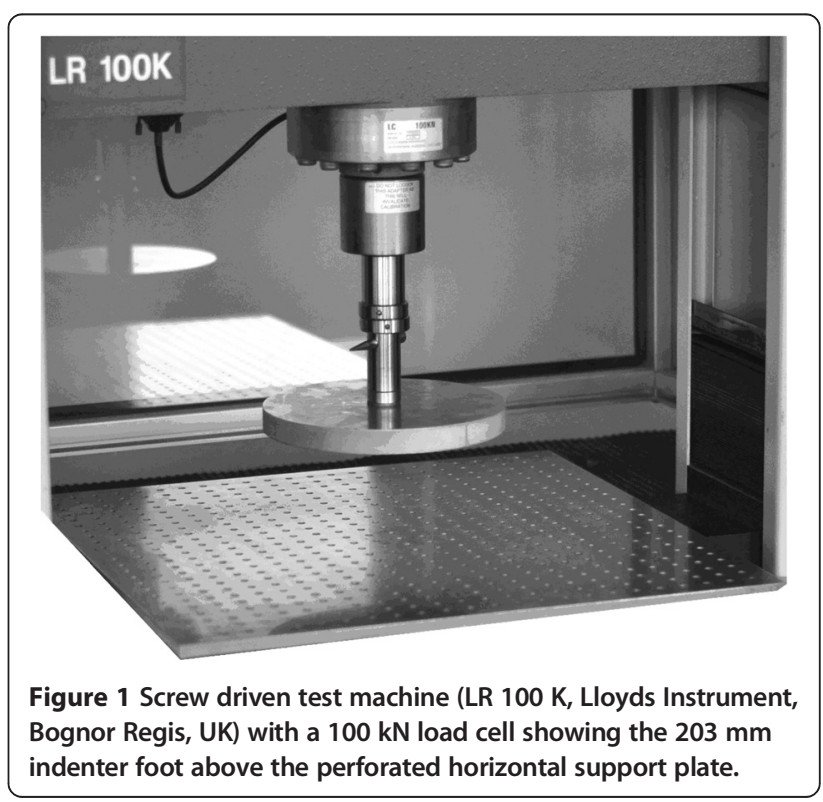


Table 1 Foam sample specification

\begin{tabular}{|c|c|c|c|c|c|c|c|}
\hline Manufacturer & Model & Type & $\begin{array}{l}\text { Size } \\
(\mathrm{mm})\end{array}$ & $\begin{array}{l}\text { Volume } \\
\left(\mathrm{m}^{3}\right)\end{array}$ & $\begin{array}{l}\text { Mass } \\
(\mathbf{k g})\end{array}$ & $\begin{array}{l}\text { Density } \\
\mathrm{kg} / \mathrm{m}^{3}\end{array}$ & $\begin{array}{l}E \\
\mathrm{kPa}\end{array}$ \\
\hline & Memory Foam & & & & & & \\
\hline \multirow[t]{3}{*}{ Vitafoam Ltd UK } & Vasco 40 & Urethane Open-Cell & $480 \times 480 \times 75$ & 0.01728 & 1.07 & 63.5 & 16.1 \\
\hline & MF-75 mm & & & & & & \\
\hline & Memory Foam & & & & & & \\
\hline \multirow[t]{2}{*}{ Vitafoam Ltd UK } & Vasco 40 & Urethane Open-Cell & $480 \times 480 \times 100$ & 0.02304 & 1.46 & 63.5 & 16.1 \\
\hline & MF-100 mm & & & & & & \\
\hline \multirow{2}{*}{ Vitafoam Ltd UK } & Reflex 35 M & Urethane Open-Cell & $480 \times 480 \times 100$ & 0.02304 & 0.86 & 37.3 & 44.9 \\
\hline & Ups-100 mm & & & & & & \\
\hline Airex AG & Balance Pads & Polyurethane & $440 \times 400 \times 50$ & 00088 & 034 & 386 & 2170 \\
\hline Speciality Foams Industrie, Switzerland & BP-50 mm & Closed-cell & $440 \times 400 \times 50$ & 0.0000 & 0.34 & 30.0 & 217.9 \\
\hline
\end{tabular}

The density was calculated by dividing the mass by the volume. $E$ was measured using the data provided by the indentation force deflection test when the specimen was compressed by $25 \%$ of its original height.

$\left(\mathrm{m}^{3}\right)$ were measured with the use of a millimetric measuring tape. The mean mass $(\mathrm{kg})$ was recorded as the average of five measurements with an electronic scale ( $\pm 1 \mathrm{~g})$ (Model 1089 BKWHDR, Salter, Hamburg). The density was calculated by the formula:

$$
\text { Density }=\mathrm{M} / \mathrm{V}
$$

where: $\mathrm{M}=$ mass of specimen, $\mathrm{kg}$, and $\mathrm{V}=$ volume of specimen, $\mathrm{m}^{3}$.

\section{Test B: indentation force deflection test (IFD)}

Based on ASTM standard D-3574-11, this test consisted of measuring the force necessary to produce a predefined indentation in the foam. A flat circular indenter with a $203 \mathrm{~mm}$ diameter foot was used to apply a load on the specimen which was supported on a level horizontal plate that was perforated with approximately $6.5 \mathrm{~mm}$ holes on approximately $20 \mathrm{~mm}$ centres to allow for rapid escape of air during the tests. From the data obtained, the modulus of elasticity was calculated for each specimen with the following formula:

$$
E=\frac{\sigma}{\varepsilon}=\frac{\frac{F}{A_{0}}}{\frac{\Delta L}{L_{0}}} \cdots \mathrm{N} / \mathrm{m}^{2}
$$

where:

$E$ is the Young's modulus (modulus of elasticity); $\sigma$ is the stress applied on the pad;

$\varepsilon$ is the strain measured from the application of $\sigma$;

$F$ is the force exerted on the foam pad

$A_{0}$ is the original cross-sectional area of the indenter through which the force is applied;

$\Delta L$ is the amount by which the height of the pad changes;

$L_{0}$ is the original height of the pad.

\section{Procedure}

The specimen was placed such that the indenter was in the centre of the apparatus' supporting plate. The area to be tested was preflexed twice by lowering the indenter's foot to a total deflection of $75 \%$ of the full part thickness at a rate of $250 \pm 25 \mathrm{~mm} / \mathrm{min}$. The specimen was allowed to rest $6 \pm 1 \mathrm{~min}$ after the preflex. The indenter was then brought into contact with the specimen by applying a $4.5 \mathrm{~N}$ load to the indenter's foot. The specimen was further indented at a rate of $50 \pm 5 \mathrm{~mm} / \mathrm{min}$ to a displacement equal to $25 \%$ of the original thickness. The force was then adjusted to retain this displacement for $60 \pm 3 \mathrm{~s}$ at which point the force measurement was taken. Without unloading the specimen, the deflection was increased to $65 \%$ deflection and once more the force was adjusted to retain this displacement for $60 \pm 3 \mathrm{~s}$ when the force was recorded.

\section{Test C: modified indentation residual gage length test - specified force (MIRGL)}

The traditional "indentation residual gage length" test force (IRGL) used to measure the thickness of the pad under a fixed force of $110 \mathrm{~N}$ and $220 \mathrm{~N}$ on a $203 \mathrm{~mm}$ diameter circular indenter foot [17]. However, these loads were not sufficient to represent the force of an adult standing on the foam pads. For this reason, the ASTM method was modified to use fixed loads of $110 \mathrm{~N}, 220 \mathrm{~N} 330 \mathrm{~N}, 440 \mathrm{~N}, 550 \mathrm{~N}, 660 \mathrm{~N}, 770 \mathrm{~N}$, 880 N, 990 N, 1100 N, 1210 N and 1320 N. Furthermore, we tested the materials with two indenter sizes: $203 \mathrm{~mm}$ diameter and $406 \mathrm{~mm}$ diameter.

\section{Procedure}

The specimen was preflexed twice with a $330 \mathrm{~N}$ force applied at $200 \pm 20 \mathrm{~mm} / \mathrm{min}$ and then allowed to rest after load removal $180 \pm 5$ sec. Foam pads were tested 
either as single layer pads (MF: memory foam; Uph: upholstery foam; BP: balance pad) or a combination of two different size bi-layer pads. The first one being a large bi-layer of $0.25 \mathrm{~m}^{2}$ surface board (MFL: Memory foam large; UphL: Upholstery foam large; BPL: balance pad large) or with a small bi-layer of $0.09 \mathrm{~m}^{2}$ surface board (MFS: Memory foam small; UphS: Upholstery foam small; BPS: balance pad small). The deflection was then recorded after the application of $110 \mathrm{~N}$ applied for $60 \pm 3 \mathrm{sec}$. The load was then increased up to $1320 \mathrm{~N}$ in steps of $110 \mathrm{~N}$, again holding for $60 \pm$ $3 \mathrm{sec}$ at each load increment. The procedures were repeated a second time with a $406 \mathrm{~cm}$ diameter indenter.

\section{Posturography}

Thirty-six healthy male factory workers (mean age $=$ 39.7 years \pm 9.3 ; mass $=88.4 \mathrm{~kg} \pm 14.1$; height $=1.78 \mathrm{~m} \pm .034$; $\mathrm{BMI}=28 \pm 3.1)$ volunteered to participate in this cross-over study. All participants were physically active and none had neurological, vestibular, visual or musculoskeletal complaints at the time of the experimentation. The participants were divided into three groups according to mass (Group 1: less than $60 \mathrm{~kg}, \mathrm{n}=5$; Group 2: $60.1 \mathrm{~kg}$ to $89.9 \mathrm{~kg}, \mathrm{n}=23$; Group 3: greater than $90 \mathrm{~kg}, \mathrm{n}=8$ ). Ethical approval was obtained for the posturography assessment from the University's Ethics committee and the procedures followed were in accordance with the ethical standards of the Helsinki Declaration of 1975, as revised in 2013 [18]. All participants read the information sheet and signed the consent form.

Postural sway velocity was recorded with the use of a force platform (QPS-200, Midot Medical Technology) linked via a USB connector to a laptop computer and the signal processed with Posture Analyser software (Midot Medical Technology). Postural sway velocities provided by the Posture Analyser software were saved in separate files on a computer.

\section{Procedure}

Posturography was measured three times for each of the 13 randomly-selected experimental situations (no foam, four samples of mono-layered foam, and eight samples of bi-layered foam). The order of each test was determined by a random sequence generator (http://www.random.org/ sequences/). The bi-layered form consisted of the foam pad covered by either a square $0.25 \mathrm{~m}^{2}$ or $0.09 \mathrm{~m}^{2}$ wooden $2 \mathrm{~cm}$ thick board. The values of the three posturographic records were averaged and used for analysis.

Participants were instructed to stand on the force platform with their feet together and eyes closed. Recording was started after 30 seconds of quiet stance. After recording was completed, participants were allowed to step off the platform and relax for one minute before the procedure was repeated two additional times. Once the three posturographic recordings were completed, the participants were asked to stand off the force platform and the experimenter changed the foam sample according to the pre-determined sequence. Posturography was again recorded. Sampling was recorded for 30 seconds [19] at $30 \mathrm{~Hz}$ per channel.

\section{Analysis}

The overall posturographic data and the participants' posturographic data grouped by mass were both tested for normality using the Shapiro-Wilk test. Descriptive statistics presented the mean sway velocity $(\bar{x})$, Interquartile range, 95\% Confidence Interval for $\bar{x}$ and sway velocity per mass category. Statistical tests were used to determine change in postural sway velocity. One-way repeated measures analyses of variance (ANOVA) with Greenhouse-Geisser corrections were used to compare postural sway velocity in the 13 experimental situations between 1) balance without foam surfaces and 2) with 12 other foam combinations. Wilcoxon-signed rank tests were used to evaluate the difference in sway velocity between mass groups. Levels of significance were set at 0.05 and the Bonferroni post-hoc test was used in the ANOVA and Wilcoxon-signed rank tests. Statistical analyses were performed using SPSS 17.0.

\section{Results}

The density of the tested samples varied from $63.5 \mathrm{~kg} / \mathrm{m}^{3}$ for the Vitafoam memory foam down to $38.6 \mathrm{~kg} / \mathrm{m}^{3}$ for the Airex balance pad. Conversely, the memory pads had a value of $E$ of $16.1 \mathrm{kPa}$ whilst the balance pad's $E$ was $217.9 \mathrm{kPa}$ (Table 1) when compressed by $25 \%$ of their original height.

The indentation force deflection test showed that memory foam pads necessitated much lower loads in order to produce a deflection of 25 and $65 \%$ of their original height. Conversely, pads with a larger $E$ required a larger force in order to achieve the same deflection as seen in Table 2.

The deformations of the foam pads during the MIRGL test using the $203 \mathrm{~mm}$ indenter were non-linear with the exception of the balance pad which showed linearity

Table 2 Indentation force deflection test (IFD)

\begin{tabular}{|c|c|c|}
\hline & \multicolumn{2}{|l|}{$203 \mathrm{~mm}$ diameter indenter } \\
\hline & $\begin{array}{l}\text { Load }(\mathrm{N}) \text { at } 25 \% \text { thickness } \\
\text { reduction }\end{array}$ & $\begin{array}{l}\text { Load }(\mathrm{N}) \text { at } 65 \% \\
\text { thickness reduction }\end{array}$ \\
\hline $\mathrm{MF}-75 \mathrm{~mm}$ & 65.2 & 169.5 \\
\hline MF-100 mm & 74.7 & 200.6 \\
\hline Uph-100 mm & 181.3 & 550.7 \\
\hline $\mathrm{BP}-50 \mathrm{~mm}$ & 880.9 & 4861.2 \\
\hline
\end{tabular}

Force necessary to produce $25 \%$ and $65 \%$ indentation on four different foam samples. MF-75 mm: memory foam $75 \mathrm{~mm}$ thickness; MF-100 mm: memory foam $100 \mathrm{~mm}$; Uph: upholstery foam $100 \mathrm{~mm}$ thickness; BP: balance pad $50 \mathrm{~mm}$ thickness. 
throughout the range of loads applied (Figure 2). Furthermore, both memory foam and upholstery pads were compressed to more than $75 \%$ of their original length when a load corresponding to an average male's weight of $770 \mathrm{~N}$ was used (Figure 2). The $406 \mathrm{~cm}$ indenter did not alter the memory foam's linearity during the MIRGL test, in contrast to the upholstery pad which showed a linear deformation from $660 \mathrm{~N}$ compression onwards with this larger indenter (Figure 3).

\section{Posturography}

The Shapiro-Wilk normality tests for changes in postural sway velocity in all participants suggested that normality was a reasonable assumption $(p>0.05)$. On the other hand, when participants' results were stratified by body mass, the velocity data was not normally distributed $(p<0.05)$. The average velocity, coefficient of variation, Interquartile range and average sway velocity according to body mass results according to each foam sample and indenter size are presented in Table 3.

A repeated measures ANOVA with a Greenhouse-Geisser correction determined that postural sway velocity differed significantly between surfaces measured $(\mathrm{F}(1.984,22.257)=$ 21926.764, $\mathrm{P}<0.0001)$. Post hoc tests using the Bonferroni correction revealed that postural sway velocity was significantly increased especially when standing on a monolayer upholstery foam and on a monolayer balance $\mathrm{pad}(75.6 \pm .18 .7 \mathrm{~mm} / \mathrm{s}$ and $78.7 \pm 13.5 \mathrm{~mm} / \mathrm{s}$ respectively) (Table 4).

Wilcoxon signed-rank tests with Bonferroni corrections showed that in three experimental situations, the postural sway velocities were significantly different in participants of different masses $(<60 \mathrm{~kg}$ vs $60-89 \mathrm{~kg}$, upholstery foam, $\mathrm{Z}=-6.156, \mathrm{p}=.009 ; 60 \mathrm{~kg} \mathrm{vs}>90 \mathrm{~kg}$, upholstery foam,

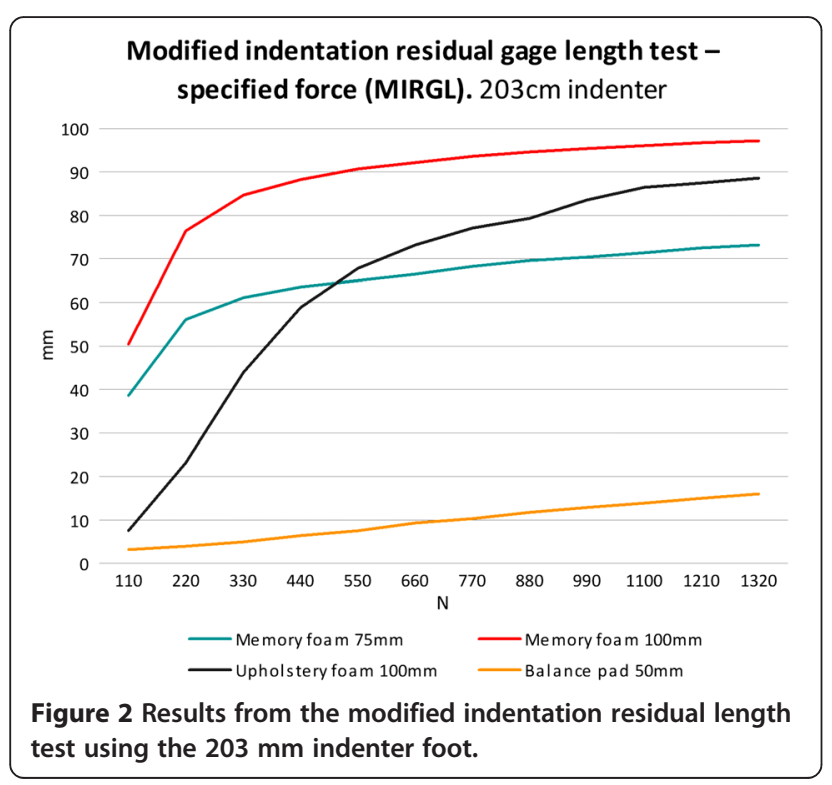

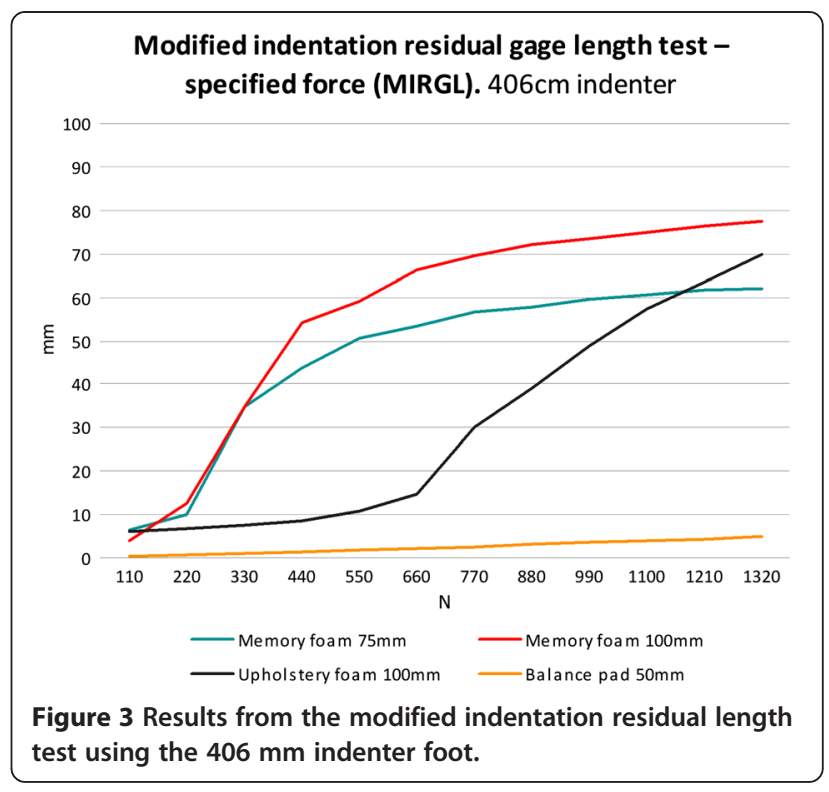

$\mathrm{Z}=-1.950, \mathrm{p}=.012 ;<60 \mathrm{~kg}$ vs $60-89 \mathrm{~kg}$, upholstery foam and large board, $\mathrm{Z}=-2.646, \mathrm{p}=.010 ; 60-89 \mathrm{~kg}$ vs $>90 \mathrm{~kg}$, upholstery foam and large board, $\mathrm{Z}=-2.521, \mathrm{p}=.012$ ).

\section{Discussion}

The objective of this project was to determine which type of foam pads were the most effective to enhance postural disturbances according to participant's weight.

\section{Foam pads}

Balance during quiet stance has been shown to be a good representation of overall system health, but not a good measure of underlying pathophysiology due to numerous contributing factors potentially affecting balance. Static posturography can be altered in different ways in order to challenge the participants to maintain a stable posture for example, narrowing the base of support by having the feet close to each other, decreasing visual feedback (closing eyes), altering the standing surface to decrease proprioceptive feedback, or introducing an accessory task or action during balance recording [20]. An increased average centre of pressure change has been associated with aging, obesity, neuropathy, Parkinson's disease, vestibular loss, stroke etc. [7,21-23]. The usefulness in using foam pads to decrease cutaneous plantar proprioception during posturographic measurement is fairly well established [11,24-26]. However, the types of foam pads used in previous experimentation has differed and it is difficult to compare results between studies. Through compression testing of different types of open cell foams using ASTM standard D-3574-95, our study has shown that stiffness varies as the material specimen cross-section changes in size relative to the indenter. We have demonstrated that foams pads, with the exception of the balance pad and the 
Table 3 Mean, coefficient of variation, interquartile range and confidence intervals for overall posturographic results and participants' results stratified by body mass

\begin{tabular}{|c|c|c|c|c|c|c|c|c|c|c|c|}
\hline \multirow{2}{*}{+2} & \multirow{2}{*}{$\overline{\mathbf{x}}(\mathrm{SD}) \mathrm{mm} / \mathrm{s}$} & \multirow[t]{2}{*}{$\mathrm{CV}$} & \multirow[t]{2}{*}{ IQR } & \multicolumn{2}{|c|}{$95 \% \mathrm{Cl}$ for $\bar{x}$} & \multicolumn{2}{|c|}{$<60 \mathrm{~kg}$} & \multicolumn{2}{|c|}{$60-89 \mathrm{~kg}$} & \multicolumn{2}{|c|}{$>90 \mathrm{~kg}$} \\
\hline & & & & & & $\overline{\bar{x}}$ & Mdn & $\overline{\bar{x}}$ & Mdn & $\overline{\bar{x}}$ & $\overline{M d n}$ \\
\hline No foam & $25.1(5.2)$ & 0.21 & 18.7 & 21.1 & 27.7 & 29.1 & 21 & 24.0 & 28.5 & 24 & 28.5 \\
\hline MF-75 mm & $23.4(6.1)$ & 0.26 & 15.5 & 19.7 & 22.6 & 27.1 & 18 & 22.3 & 27.1 & 21 & 25.5 \\
\hline MF-100 mm & $22.3(4.9)$ & 0.22 & 14.7 & 18.4 & 21.4 & 26.1 & 17 & 21.2 & 25.8 & 20 & 24.5 \\
\hline Uph-100 mm & $75.6(7.4)$ & 0.10 & 23.2 & 69.2 & 85.7 & 81.9 & 82 & 82.1 & 49.5 & 45 & 49.5 \\
\hline $\mathrm{BP}-50 \mathrm{~mm}$ & $78.7(7.1)$ & 0.09 & 23.7 & 74.1 & 82.7 & 83.2 & 79 & 82.0 & 66.5 & 62 & 66.5 \\
\hline MFL-75 mm & $27.0(4.6)$ & 0.17 & 18.3 & 23.1 & 27.7 & 30.9 & 24 & 26.1 & 28.8 & 24.3 & 28.8 \\
\hline MFL-100 mm & $32.8(6.9)$ & 0.21 & 18.7 & 28.8 & 29.7 & 36.8 & 36 & 31.4 & 30.5 & 26 & 30.5 \\
\hline UphL-100 mm & $64.5(6.3)$ & 0.10 & 24.5 & 59.3 & 67.7 & 69.7 & 64 & 57.0 & 81.4 & 76 & 81.4 \\
\hline BPL-50 mm & $33.0(2.5)$ & 0.08 & 19.75 & 29.2 & 33.7 & 36.9 & 30 & 33.0 & 32.5 & 28 & 32.5 \\
\hline MFS-75 mm & $25.5(6.6)$ & 0,25 & 19.1 & 21.4 & 26.8 & 29.6 & 21.4 & 24.4 & 28.7 & 24.1 & 28.6 \\
\hline MFS-100 mm & $29.0(5.3)$ & 0.18 & 18.5 & 24.5 & 42.7 & 33.4 & 39 & 24.6 & 28.6 & 23.5 & 28.0 \\
\hline Uphs-100 mm & $48.4(3.7)$ & 0.07 & 20.5 & 43.6 & 44.7 & 53.3 & 41 & 44.0 & 63.5 & 59 & 63.5 \\
\hline BPS-50 mm & $34.0(3.1)$ & 0.09 & 19.8 & 30.0 & 34.7 & 38.1 & 31 & 34.0 & 33.5 & 29 & 33.5 \\
\hline
\end{tabular}

$\bar{x}(\mathrm{SD})=$ average velocity and its standard deviation. $\mathrm{IQR}=$ Interquartile range. $\mathrm{Cl}-95 \%$ confidence interval for the average velocity of sway.

MF: memory foam; Uph: upholstery foam; BP: balance pad; Large bi-layer with a surface of $0.25 \mathrm{~m}^{2}$ board: MFL: Memory foam large; UphL: Upholstery foam large; BPL: balance pad large; Small bi-layer with a surface of $0.09 \mathrm{~m}^{2}$ : MFS: Memory foam small; UphS: Upholstery foam small; BPS: balance pad small.

upholstery foam with the $406 \mathrm{~mm}$ indenter, did not show linear deformation throughout the range of loads used in the MIRGL with both the $203 \mathrm{~mm}$ and $406 \mathrm{~mm}$ indenters. Both memory foam pads failed to resist the compression at relatively low loads which suggested they would not provide sufficient resistance to compression during posturography for healthy adult participants. Their compression slopes during the MIRGL clearly show a trend towards asymptotic displacement beyond $220 \mathrm{~N}$ for the memory foam and beyond $660 \mathrm{~N}$ compression for the mono-layer upholstery foam. Non-linear stress-strain relationships were observed

Table 4 ANOVA Pairwise comparison between velocity of sway without foam and with different foam surfaces

\begin{tabular}{|c|c|c|c|c|}
\hline \multirow[b]{2}{*}{ Mono-layer } & \multirow[b]{2}{*}{ MF-75 mm } & \multirow{2}{*}{$\begin{array}{l}\boldsymbol{p} \\
\mathrm{ns}\end{array}$} & \multicolumn{2}{|c|}{$\begin{array}{l}95 \% \mathrm{Cl} \text { for difference } \\
\text { with no foam }\end{array}$} \\
\hline & & & -0.3 & 3.7 \\
\hline & MF-100 mm & .002 & 0.6 & 5.0 \\
\hline & Uph-100 mm & .000 & -61.0 & -39.9 \\
\hline & $\mathrm{BP}-50 \mathrm{~mm}$ & .000 & -58.8 & -48.2 \\
\hline \multirow[t]{4}{*}{ Bi-layer $0.09 \mathrm{~m}^{2}$} & MFL-75 mm & .030 & -3.6 & -0.08 \\
\hline & MFL-100 mm & ns & -15.1 & -0.2 \\
\hline & UphL-100 mm & .000 & -44.5 & -34.1 \\
\hline & BPL-50Lmm & .000 & -9.2 & -6.5 \\
\hline \multirow[t]{4}{*}{ Bi-layer $0.25 \mathrm{~m}^{2}$} & MFS-75 mm & ns & -2.2 & 0.8 \\
\hline & MFS-100 mm & ns & -8.4 & 0.6 \\
\hline & UphS-100 mm & .000 & -27.2 & -19.3 \\
\hline & BPS-50 mm & .000 & -10.2 & -7.5 \\
\hline
\end{tabular}

ns = not significant. due to the changes in the foam geometry at high strains. When the foam is highly compressed the foam volume tends to zero and the stiffness tends to infinity. Patel suggested that such large compression (as observed with the memory foam here) would result in the participants coming in to close contract with the rigid surface beneath the foam [13]. The balance pad showed a largely linear response throughout the loads applied during the MIRGL test. Conversely, the upholstery foam exhibited a bi-linear type of behaviour when compressed with the $406 \mathrm{~mm}$ diameter indenter. It supported the load with minimum deformation up to $660 \mathrm{~N}$, at which point it gave way and deformed with a lower stiffness up to the maximum load.

Our results show that foam pads can indeed increase the postural sway velocity of healthy participants, in some cases significantly. Participants standing on foam pads did elevate their centre of mass by nearly $50 \mathrm{~mm}$ corresponding to less than $3 \%$ of the participants' average height. The force platform used in this project consisted of 4 weighing plates, and the CoP is calculated from the resultant force, with the velocity calculated by the change in the CoP position. It is therefore unlikely that elevating the centre of mass would have affected appreciably the postural sway velocity results. When participant data were stratified according to mass, results showed that the balance pad did still produce the largest increase in sway velocity in Groups 1 and 2, in the heavier Group 3 (mass $>90 \mathrm{~kg}$ ), the large bi-layer upholstery foam pad had the largest effect. The pairwise comparison between sway velocities without foam and with foam surfaces showed a large confidence interval, 
which can be attributed to the separation of participants into smaller groups according to mass. The null hypothesis stating "there is no difference in sway velocity when any of the foam pads are used" can thus be rejected. Furthermore, our participants were male factory workers with a mean BMI of 28 which is slightly higher than the UK male average [27]. Athletes presenting the same mass but with a more mesomorphic body type might have provided different results.

It is interesting to note that not only was there no significant difference between posturographic results between "no foam" and samples of $75 \mathrm{~mm}$ and $100 \mathrm{~mm}$ thick memory foam samples, but the sway velocity was somewhat improved when memory foam pad were used. A learning effect explanation can be excluded in view of the random order of the test conducted. We concluded that because the participants' feet had a smaller crosssectional area than the pads onto which they were standing on and the fact that our participants nearly flattened the pads meant a shear force was created between the material and the sides of the feet as the specimen deformed. This would have increased the surface area of contact between the foam pads and the side of the feet which in turn would most likely have increased proprioception thereby providing additional cues and improving balance. With participants of larger mass, as the deflection increased, the memory foam could actually have provided an advantage in the posturographic task. Thus, when selecting a type of foam pad to be used in posturography, it is recommended that investigators select samples appropriate to their participants' weight. For instance, in the selection of foam pads for individuals weighting more than $900 \mathrm{~N}$, a bi-layer upholstery foam pad of around $37.3 \mathrm{kPa}$ and $44.9 \mathrm{kPa}$ such as used in our experiment would be the appropriate choice. Additionally, it may be of importance to select a foam pad presenting limited deflection under loading in order to avoid contact of the feet with the sides of the material.

\section{Conclusion}

The Balance pad produced the largest postural sway velocity in participants with less than $90 \mathrm{~kg}$ mass whilst the bi-layer upholstery sample (406 $\mathrm{mm}$ indenter) produced the largest changes in participants above $90 \mathrm{~kg}$ of mass. The results suggest that foam pads selected for static computerised posturography: 1) could possess a modulus of elasticity of around $40 \mathrm{~kg} / \mathrm{m}^{3}$, and 2) show linear deformation properties matched to the participants' weight.

\section{Competing interests}

The authors declare that they have no competing interests.

\section{Authors' contributions}

GG designed, executed and analysed the entire experiment and prepared the manuscript. MF assisted in design and testing materials. Both authors read and approved the final manuscript.

Received: 20 June 2014 Accepted: 20 November 2014

Published online: 19 January 2015

\section{References}

1. Punakallio A. Balance abilities of different-aged workers in physically demanding jobs. J Occup Rehabil. 2003;13(1):33-43.

2. Wu X, Madigan ML. Impaired plantar sensitivity among the obese is associated with increased postural sway. Neurosci Lett. 2014;583:49-54

3. Forsman P, Wallin A, Haeggstrom E. Validation of a posturographic approach to monitor sleepiness. J Biomech. 2010;43(16):3214-6.

4. Zamyslowska-Szmytke E, Sliwinska-Kowalska M. The influence of organic solvents on hearing and balance: a literature review. Med Pr. 2013;64(1):83-102.

5. Munnell A. What is the Average Retirement Age? Chestnut Hill, MA: Centre for Retirement Research, Boston College; 2011.

6. St-Pierre F. Analysis of Static and/or Dynamic Posture on a Force Platform (Posturography). St-Denis la Plaine, France: Department of Medical and Surgical Procedures Assessment, Haute Authorite de Sante; 2007.

7. Mitchell RJ, Lord SR, Harvey LA, Close JCT. Obesity and falls in older people: mediating effects of disease, sedentary behaviour, mood, pain and medication use. Arch Gerontol Geriatr 2014 Sep 22. doi:10.1016/j. archger.2014.09.006. [Epub ahead of print].

8. Chaudhry H, Bukiet B, Ji Z, Findley T. Measurement of balance in computer posturography: comparison of methods-a brief review. J Bodyw Mov Ther. 2011;15(1):82-91.

9. Mahdavi-Amiri N, Bidabadi N. Constrained nonlinear least squares: a superlinearly convergent projected structured secant method. Int J Electrical Comput Syst. 2012;1(1):1-8.

10. Wade C, Davis J, Weimar WH. Balance and exposure to an elevated sloped surface. Gait Posture. 2014;39(1):599-605.

11. Di Berardino F, Filipponi E, Barozzi S, Giordano G, Alpini D, Cesarani A. The use of rubber foam pads and "sensory ratios" to reduce variability in static posturography assessment. Gait Posture. 2009;29(1):158-60.

12. Gosselin G, Fagan MJ. The effects of cervical muscle fatigue on balance a study with elite amateur rugby league players. J Sports Sci Med. 2014;13(2):329-37.

13. Patel M, Fransson PA, Lush D, Gomez S. The effect of foam surface properties on postural stability assessment while standing. Gait Posture. 2008;28(4):649-56.

14. Todd BA, Smith SL, Vongpaseuth T. Polyurethane foams: effects of specimen size when determining cushioning stiffness. J Rehabil Res Dev. 1998;35 (2):219-24.

15. Blackburn JT, Riemann BL, Myers JB, Lephart SM. Kinematic analysis of the hip and trunk during bilateral stance on firm, foam, and multiaxial support surfaces. Clin Biomech (Bristol, Avon). 2003;18(7):655-61.

16. Adkin AL, Bloem BR, Allum JH. Trunk sway measurements during stance and gait tasks in Parkinson's disease. Gait Posture. 2005;22(3):240-9.

17. D-3574-11 AS. Standard Methods of Testing Flexible Cellular MaterialsSlab, Bonded and Molded Urethane Foams. Philadelphia: American Society for Testing and Materials; 2012. p. 18.

18. World Medical A. World medical association Declaration of Helsinki: ethical principles for medical research involving human subjects. JAMA. 2013;310 (20):2191-4.

19. Prosperini L, Fortuna D, Gianni C, Leonardi L, Pozzilli C. The diagnostic accuracy of static posturography in predicting accidental falls in people with multiple sclerosis. Neurorehabil Neural Repair. 2013;27(1):45-52.

20. Mancini M, Horak FB. The relevance of clinical balance assessment tools to differentiate balance deficits. Eur J Phys Rehabil Med. 2010;46(2):239-48.

21. Prieto T. Measures of postural steadiness: differences between healthy young and elderly adults. IEEE Trans Biomed Eng. 1996;43(9):956-66.

22. Hung J-W, Chou C-X, Hsieh Y-W, Wu W-C, Yu M-Y, Chen P-C, et al. Randomized comparison trial of balance training by using exergaming and conventional weight-shift therapy in patients with chronic stroke. Arch Phys Med Rehabil. 2014;95(9):1629-37.

23. Nardone A, Godi M, Artuso A, Schieppati M. Balance rehabilitation by moving platform and exercises in patients with neuropathy or vestibular deficit. Arch Phys Med Rehabil. 2010;91(12):1869-77. 
24. Chiang JH, Wu G. The influence of foam surfaces on biomechanical variables contributing to postural control. Gait Posture. 1997;5(3):239-45.

25. Allum JH, Honegger F. Interactions between vestibular and proprioceptive inputs triggering and modulating human balance-correcting responses differ across muscles. Exp Brain Res. 1998;121(4):478-94.

26. Liu B, Kong W. Reliability of foam posturography in assessment of postural balance in the patients with vertigo. Front Med China. 2008;2(4):361-5.

27. Finucane MM, Stevens GA, Cowan MJ, Danaei G, Lin JK, Paciorek CJ, et al. National, regional, and global trends in body-mass index since 1980: systematic analysis of health examination surveys and epidemiological studies with 960 country-years and 9.1 million participants. Lancet. 2011;377 (9765):557-67.

\section{Submit your next manuscript to BioMed Central and take full advantage of:}

- Convenient online submission

- Thorough peer review

- No space constraints or color figure charges

- Immediate publication on acceptance

- Inclusion in PubMed, CAS, Scopus and Google Scholar

- Research which is freely available for redistribution 